\title{
Linkage Analysis of Fifty-Seven Microsatellite Loci to Bipolar Disorder
}

Pablo V. Gejman, M.D., Maria Martinez, Ph.D., Qiuhe Cao, M.D., Eitan Friedman, M.D., Wade H. Berrettini, M.D., Ph.D., Lynn R. Goldin, Ph.D., Panayiota Koroulakis, Chris Ames, Melissa A. Lerman, and Elliot S. Gershon, M.D.

The authors' goal was to screen for genetic linkage with highly informative deoxyribonucleic acid (DNA) imosatellite markers on a series of moderately sized North American bipolar disorder (BP) pedigrees. These BP pedigrees were genotyped with 57 short tandemneot polymorphic systems (microsatellites) that were oxymetically amplified from genomic DNA. We did not pid significant evidence for genetic linkage. We found isolated LOD scores greater than 2 on chromosome 1 at two loci in individual pedigrees. Simulation studies for multiple analyses under the assumptions of linkage and nonlinkage were performed. The simulations show that LOD scores greater than 2 could be expected even when linkage is absent. Significance levels need to be considered carefully in systematic linkage studies. [Neuropsychopharmacology 9:31-40, 1993]
Tr worDs: Mapping; Bipolar illness; Microsatellites; Cnetic linkage simulations; GNAS1; Human X-linked GABA-A receptor a3-subunit gene

Abody of epidemiologic studies implies that there is renetic component that confers susceptibility to bipotdisorder (BP) (Numberger et al. 1986). However, exaination of the distribution of illness in families shows th it is improbable that a single defective gene comwety determines whether a person shows the disease phenotype, because the mode of genetic transmission dBP does not follow simple Mendelian rules. Several trusble theories explaining the pathophysiology of Phave been proposed, but without full support from aperimental evidence, and it may be argued that the

From the Cinical Neurogenetics Branch, National Institute of Mental When (PVG, QC, LRG, PK, CA, MAL, ESG), Bethesda, Maryland; denologie Génétique, Institut National de la Santé et de la Re-riche Medicale (MM), Paris, France; Department of Clinical Cotics, Karolinska Hospital (EF), Stockholm, Sweden; and Dpertment of Psychiatry and Human Behavior, Jefferson Medical Corge, Thomas Jefferson University (WHB) Philadelphia, Pennsylin.

Adress correspondence to: Pablo V. Gejman, M.D., CNG/NIMH, EsN218, Bethesda, Maryland 20892.

hoved August 27, 1992; revised January 4, 1993; accepted January a. 1933 . field lacks solid candidate genes (Numberger et al. 1986). In this context, identification of susceptibility genes by the use of genetic linkage analysis strategies that do not require an a priori knowledge of the pathophysiology of BP become an attractive research alternative. Furthermore, genetic linkage methods can detect a susceptibility gene when the exact manner of transmission is not known (Clerget-Darpoux et al. 1986). The effects of misspecification of genetic parameters in pairwise analysis is generally modest: linkage is detected but the recombination fraction is biased (Clerget-Darpoux et al. 1986). The magnitude of bias will depend upon the true and the assumed values of the genetic parameters.

Berrettini et al. (1991a) described a series of 21 pedigrees with BP. Genetic linkage of illness in this pedigree series has been examined in previously published papers for 107 markers on chromosomes 1, 10q, 11q, 13, 15, and 17 (Berrettini et al. 1991b), for 24 markers on chromosome 5 in 14 of these pedigrees (DeteraWadleigh et al. 1992), and for five markers on Xq27-28 in a subset of families in which segregation of BP is consistent with X-chromosome transmission (Berrettini et al. 1990; Gejman et al. 1990), with classic restriction fragment length polymorphism (RFLP) markers used for 
nearly all loci. Here we report linkage analyses of 57 additional markers, all microsatellites, to BP.

The power of this or any pedigree series to detect linkage, when it exists, is a function of the pedigree structures, the complexity of genetic transmission, the proportion of cases linked, and the informativeness of the marker loci. Informativeness refers to the genetic variation of the markers. It is commonly measured by the frequency of heterozygotes at a locus and expressed in terms of heterozygosity. High heterozygosity values (greater than $70 \%$ ) permit a more complete genetic analysis of the affected families because the segregation of the disease and marker can be analyzed in a larger number of meioses. Deoxyribonucleic acid (DNA) markers with high heterozygosity are specially useful when the number of pedigrees that can be studied is limited, as is often the case.

The polymerase chain reaction (PCR) allows inexpensive and rapid genotyping of a large number of individuals with minimum effort. Polymerase chain reaction is used to enzymatically amplify marker loci with high-average heterozygosity, dispersed throughout the genome. These have recently become available through the discovery of dinucleotide tandem repeats (microsatellites) of the form $(\mathrm{dC}-\mathrm{dA})_{\mathrm{n}} \cdot(\mathrm{dG}-\mathrm{dT})_{\mathrm{n}}$ (Weber and May 1989). These sequences display highly variable numbers of dinucleotide repeats, which show up on denaturing polyacrylamide gels as length polymorphisms.

The recent availability of microsatellite markers, which might reasonably be expected to be randomly dispersed, offer an opportunity to add significantly to the number of markers mapped in this series of pedigrees. We decided to exploit the opportunity as a "first pass" with later incorporation of data into systematic chromosomal scanning for susceptibility loci when this is appropriate, such as when gaps in the known genetic map can be filled with these markers. In published papers, linkage analysis to microsatellites located in chromosomes not yet scanned can be considered a "first pass."

Genetic linkage in this pedigree series has been previously examined systematically using mapped markers on several chromosomes. Linkage analyses to microsatellites located in these chromosomal regions should be considered a "second pass" that can provide more information at particular loci or fill in gaps in the genetic maps. An example of a successful "second pass" tactic is the detection of linkage between a microsatellite locus (D4S171) and facioscapulohumeral dystrophy disease in the distal long arm of chromosome 4 after a large portion of the genome had been excluded by using traditional DNA markers (Wijmenga et al. 1990). Linkage had not been previously detected because no markers were available in the region of linkage.

\section{METHODS}

We have studied a series of moderately sized North American pedigrees, whose structures, ascertainment, diagnostic procedures, extension rules, and expected LOD scores in linkage analyses are described elsewhere (Berrettini et al. 1991a). When a LOD score appeared positive (see below), we added the "right extension" (Kelsoe et al. 1990) of the Old Order Amish BP pedigree 110 for additional information.

\section{Affection Status Models}

The following are affection status models of who is ill or well (Berrettini et al. 1991a). Model 1: Either Bipolar I, Bipolar II with major depression, or schizoaffective disorder. Model 2: Model 1 plus recurrent (more than 1 episode) unipolar disorder. Model 3: Model 2 plus any of the following; nonrecurrent (one episode) unipolar; suicide; cyclothymic personality; Bipolar II with minor depression; unspecified functional psychosis, suicide, hypomania, anorexia, bulimia, other psychiatric disorder (hospitalized), and schizophrenia. Persons with affective disorders associated with brain dysfunction, including cerebrovascular accident or brain tumor, are considered as phenotype unknown.

For linkage analysis, persons considered affected only under model 3 were classified as unaffected when linkage calculations were performed for models 1 and 2 , and persons considered affected only under model 2 were classified as unaffected for the calculations for model 1. However, because the precise inheritance of the BP phenotype is not known with certainty, the affer. tion classification models used by us should be considered educated working hypotheses founded in epi. demiologic data. When LOD scores suggested possible genetic linkage, a variation of these models was followed: the phenotype of persons considered affected under a less stringent model was classified as unknown in the calculations.

\section{DNA Amplification and Electrophoresis}

Polymerase chain reaction was performed in a total vol ume of $15 \mu \mathrm{l}$ using approximately $0.15 \mu \mathrm{g}$ of genomis DNA, $200 \mu \mathrm{mol}$ each of adenosine triphosphate, guano sine triphosphate, and thymidine triphosphate, 2.5 $\mu \mathrm{mol}$ of cytidine triphosphate, $0.03 \mu \mathrm{Ci}$ of cytidine triphosphate [ ${ }^{\alpha-32}$ ]phosphate $(3000 \mathrm{Ci} / \mathrm{mmol}), 5$ pmol

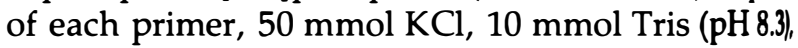
$1.5 \mathrm{mmol} \mathrm{MgCl}_{2}, 0.01 \%$ gelatin, $0.25 \mathrm{mmol}$ spermidine, and 0.10 unit of Taq polymerase (Perkin Elme Cetus). Typically, two sets of primers were included in each reaction (multiplexing). In a few experiments, only one set of PCR primers was used. Samples wert 
overlaid with $20 \mu$ l of mineral oil and were processed though 20 temperature cycles (denaturation, annealin and extension) consisting of 50 seconds at $92^{\circ} \mathrm{C}$, Neconds at $52^{\circ} \mathrm{C}$, and 90 seconds at $72^{\circ} \mathrm{C}$. In the last mede, the extension step was lengthened to 4 minutes. Polymerase chain reaction was performed in microti- plates in a Techne thermocycler (MW2). Polymerschain reaction aliquots were electrophoresed on $6 \%$ b $8 \%$ denaturing polyacrylamide DNA sequencing els. Gel size standards were dideoxy sequencing ladders(M13mp18 template). Gels were fixed, dried, and wtoradiographed for 1 to 4 days. Oligonucleotide pimers were synthesized on a DNA synthesizer (Cydone Plus, Milligen/Biosearch, Millipore).

\section{Conotyping and Linkage Analysis}

Unembers of 19 families in the pedigree series had amthed DNA arranged on a gel in a fixed order by fami. Each autoradiogram was uniquely identified with meprinted labels. The bands were read independently by two persons, and the readings recorded on the indicod column on two separate sheets. We carefully exained the quality of each autoradiogram generated with every experiment before deciding to include it in database of genotypes. If this first level of scrutiny mos successfully passed, the two separate readings rere entered into a computer database that detects the prence of differences between the entries. Resolution inconsistencies was done by reinspecting the auundiograms, and in instances where they remained cursolved, the genotypes (of individuals, sibships, or milies at a given locus) were considered unknown. Thenever a sample of genomic DNA was found to sysmatically give genotypes inconsistent with the rest the family, this batch was discarded and another one mo obtained.

A subset of seven families in which the segregamof BP is consistent with $\mathrm{X}$-chromosome, transmis$\min (0016,0024,0065,0068,0278$, and 0643) was typed with the human X-linked gamma-aminobutyric acid-A cocptor a3-subunit gene (see, Gejman et al. 1990; Beratiniet al. 1990 for description of families and absence dmale-to-male transmission).

linkage analyses were performed with the LINKACE package version 5.03 (Lathrop et al. 1985). The oumed genetic transmission model of disease was minant with a susceptibility allele frequency of 0.01 . Poretrance values varied according to age: six susceprity classes were considered. Penetrances for disease pare carriers varied from $17 \%$ to $85 \%$. It could be arpod that othergenetic models should be examined bewe the mode of transmission of BP is unknown. Famin our sample were selected because they have a re number of affecteds in successive generations.
Thus, the assumption of the dominant mode of inheritance seems reasonable when screening markers for linkage. Other models may be analyzed in a future publication. The penetrance for noncarriers was set to vary from 0.001 to 0.01 . This implies that the assumed rate of phenocopies increases with age and was different from the penetrances previously assumed (Berrettini et al. 1991a). At young ages, the rate of phenocopies is $22 \%$, but at older ages the rate of phenocopies increases up to $37 \%$. Our model, with some particular family structures that include affected individuals located in the higher phenocopy penetrances class, would lead to less extreme LOD scores than previously calculated (Berrettini et al. 1991b). We assumed equal recombination in males and females for the initial analysis.

LOD score calculations were done under the three affection status models, with recombination fractions $(\theta)$ from 0 to 0.3 . In a pedigree series such as ours, where heterogeneity may be present, we examined the total LOD score in pairwise analysis, followed by examination of the individual LOD scores in each pedigree.

\section{RESULTS}

Table 1 shows the chromosomal location and the polymorphism information content (PIC) of microsatellites used in these analyses and the total LOD scores under homogeneity at each locus $\theta=0, \theta=0.10$, and $\theta=$ 0.20).

Although all individuals had DNA amplified, not all persons yielded technically acceptable genotypes. An average of 261.2 individual genotypes ( $81 \%$ of individuals) per microsatellite system with a standard deviation of 67.6 were entered into the data base. A strict criterion for selecting data to be included in the calculations accounts for the individuals who were not typed (see section on genotyping and linkage analysis). Twelve loci had more than 300 individuals genotyped (19 families typed per locus). Less than 100 individuals have been typed with one microsatellite system, D8S87 (87 individuals typed in six families). Between 110 and 150 individuals were typed at seven loci (D17S250, D19S47, D19S48, D2S72, D22S156, D4S171, and D4S74). We have excluded genetic linkage under homogeneity at most of the loci at a distance of 10 to $20 \mathrm{cM}$.

We computed the power to detect linkage under heterogeneity using the program SIMLINK (Smith 1963; Ploughman and Boehnke 1989) for three different sample sizes corresponding to the number of individuals actually genotyped in three representative experiments. We assumed the same genetic parameters as those used for the pairwise analyses and that half of the families had an illness gene linked to a marker. For a marker with PIC $=0.7$ and $\theta=0.01$, the power 
Table 1. Assumed Genetic Model of Disease*

\section{LOD Scores}

\begin{tabular}{|c|c|c|c|c|c|c|c|}
\hline \multirow{3}{*}{ Locus Name } & \multirow[b]{3}{*}{ Chromosome } & \multirow{3}{*}{$\begin{array}{c}\text { Regional } \\
\text { Localization }\end{array}$} & \multirow{3}{*}{$\begin{array}{c}\text { PIC or } \\
\text { Heterozygosity }\end{array}$} & \multirow{3}{*}{$\begin{array}{c}\text { Affection } \\
\text { Status Model }\end{array}$} & \multirow{2}{*}{\multicolumn{3}{|c|}{ Recombination Fraction }} \\
\hline & & & & & & & \\
\hline & & & & & $\theta=0$ & $\theta=0.10$ & $\theta=0.20$ \\
\hline \multirow[t]{2}{*}{ D1S103 } & 1 & & 0.78 & 1 & -15.70 & -3.98 & -1.15 \\
\hline & & & & 2 & -15.62 & -1.93 & 0.83 \\
\hline \multirow[t]{2}{*}{ D1S104 } & 1 & $1 q 21-q 23$ & 0.66 & 1 & -6.44 & -1.34 & -0.02 \\
\hline & & & & 2 & -15.01 & -3.80 & -1.05 \\
\hline \multirow[t]{2}{*}{ CRP } & 1 & $1 q 21-q 23$ & 0.53 & 1 & -15.39 & -5.13 & -0.86 \\
\hline & & & & 2 & -20.12 & -4.53 & -0.34 \\
\hline \multirow[t]{2}{*}{ D1S117 } & 1 & $1 q 23-q 25$ & 0.77 & 1 & -10.41 & -3.79 & -1.32 \\
\hline & & & & 2 & -24.42 & -8.68 & -3.53 \\
\hline \multirow[t]{2}{*}{ D2S72 } & 2 & & 0.71 & 1 & -9.15 & -3.66 & -1.74 \\
\hline & & & & 2 & -7.99 & -2.76 & -1.21 \\
\hline \multirow[t]{2}{*}{ D3S196 } & 3 & & 0.68 & 1 & -13.23 & -3.39 & -1.04 \\
\hline & & & & 2 & -16.21 & -3.91 & -1.20 \\
\hline D3S240 & 3 & & 0.30 & 1 & -1.58 & -0.50 & 0.10 \\
\hline & & & & 2 & -2.71 & -1.10 & -0.31 \\
\hline GLUT2 & 3 & $3 q 26.1-q 26.3$ & & 1 & -14.35 & -4.53 & -1.54 \\
\hline & & & & 2 & -17.45 & -5.42 & -2.22 \\
\hline D4S174 & 4 & & 0.86 & 1 & -5.93 & -1.08 & -0.02 \\
\hline & & & & 2 & -9.00 & -0.97 & 0.70 \\
\hline FABP2 & 4 & $4 q 28-q 31$ & $64 \%$ & 1 & -15.73 & -5.89 & -2.90 \\
\hline & & & & 2 & -15.84 & -4.41 & -1.57 \\
\hline D5S108 & 5 & & 0.45 & 1 & -3.09 & 0.03 & 0.56 \\
\hline & & & & 2 & -6.25 & -0.74 & 0.24 \\
\hline D5S117 & 5 & & 0.62 & 1 & -8.10 & -4.71 & -2.32 \\
\hline & & & & 2 & -15.53 & -9.08 & -4.39 \\
\hline D5S118 & 5 & & 0.48 & 1 & -9.82 & -2.26 & -0.32 \\
\hline & & & & 2 & -16.53 & -4.10 & -1.03 \\
\hline D5S119 & 5 & & 0.50 & 1 & -8.95 & -3.06 & -1.38 \\
\hline & & & & 2 & -14.33 & -4.83 & -1.81 \\
\hline D5S107 & 5 & $5 q 11.2-q 13.3$ & 0.78 & 1 & -11.01 & -3.80 & -1.63 \\
\hline & & & & 2 & -20.33 & -6.23 & -2.73 \\
\hline CFS1R & 5 & $5 q 33.3-34$ & 0.85 & 1 & -27.00 & -8.96 & -3.81 \\
\hline & & & & 2 & -36.33 & -12.65 & -5.60 \\
\hline D6S87 & 6 & & 0.53 & 1 & -9.16 & -1.81 & -0.31 \\
\hline & & & & 2 & -18.84 & -5.16 & -1.67 \\
\hline D7S435 & 7 & & 0.53 & 1 & -16.25 & -5.32 & -2.46 \\
\hline & & & & 2 & -22.70 & -5.55 & -1.95 \\
\hline D8S87 & 8 & 8p12 & 0.71 & 1 & -3.38 & -1.48 & -0.33 \\
\hline & & & & 2 & -4.96 & -1.97 & -0.33 \\
\hline D8S84 & 8 & $8 q 12-q 13$ & 0.58 & 1 & -18.05 & -6.07 & -2.60 \\
\hline & & & & 2 & -20.75 & -6.23 & -2.21 \\
\hline D9S43 & 9 & & 0.74 & 1 & -9.09 & -1.60 & -0.06 \\
\hline & & & & 2 & -14.82 & -4.80 & -2.05 \\
\hline ASS & 9 & $9 q 34$ & $64 \%$ & 1 & -20.82 & -6.28 & -2.28 \\
\hline & & & & 2 & -32.59 & -9.37 & -3.72 \\
\hline D10S89 & 10 & & 0.71 & 1 & -14.41 & -3.61 & -1.24 \\
\hline & & & & 2 & -22.34 & -5.97 & -2.18 \\
\hline D11S419 & 11 & & 0.43 & 1 & -6.31 & -1.37 & -0.10 \\
\hline & & & & 2 & -8.92 & -2.76 & -0.99 \\
\hline D11S35 & 11 & $11 q 22$ & 0.79 & 1 & -13.30 & -3.71 & -1.30 \\
\hline & & & & 2 & -10.89 & -1.63 & -0.03 \\
\hline CD3D & 11 & $11 q 23$ & 0.69 & 1 & -16.22 & -5.56 & -2.11 \\
\hline & & & & 2 & -19.18 & -5.74 & -1.99 \\
\hline D11S420 & 11 & 11q23.3-q24 & 0.66 & 1 & -14.62 & -5.25 & -2.39 \\
\hline & & & & 2 & -19.15 & -6.49 & -2.93 \\
\hline D12S43 & 12 & & 0.71 & 1 & -13.83 & -5.87 & -3.08 \\
\hline & & & & 2 & -20.39 & -7.71 & -3.91 \\
\hline PLA2 & 12 & & 0.73 & 1 & -18.65 & -5.70 & -2.17 \\
\hline & & & & 2 & -24.90 & -7.80 & -2.92 \\
\hline IGF1 & 12 & $12 \mathrm{q} 22-\mathrm{q} 24.1$ & 0.53 & 1 & -8.15 & -2.97 & -1.51 \\
\hline & & & & 2 & -9.42 & -2.62 & -1.04 \\
\hline D13S71 & 13 & & 0.67 & 1 & -13.83 & -5.87 & -3.08 \\
\hline & & & & 2 & -20.39 & -7.71 & -3.91 \\
\hline FLT1 & 13 & $13 q 12$ & 0.49 & 1 & -5.39 & -0.83 & 0.65 \\
\hline & & & & 2 & -7.40 & -0.55 & 0.4 \\
\hline
\end{tabular}




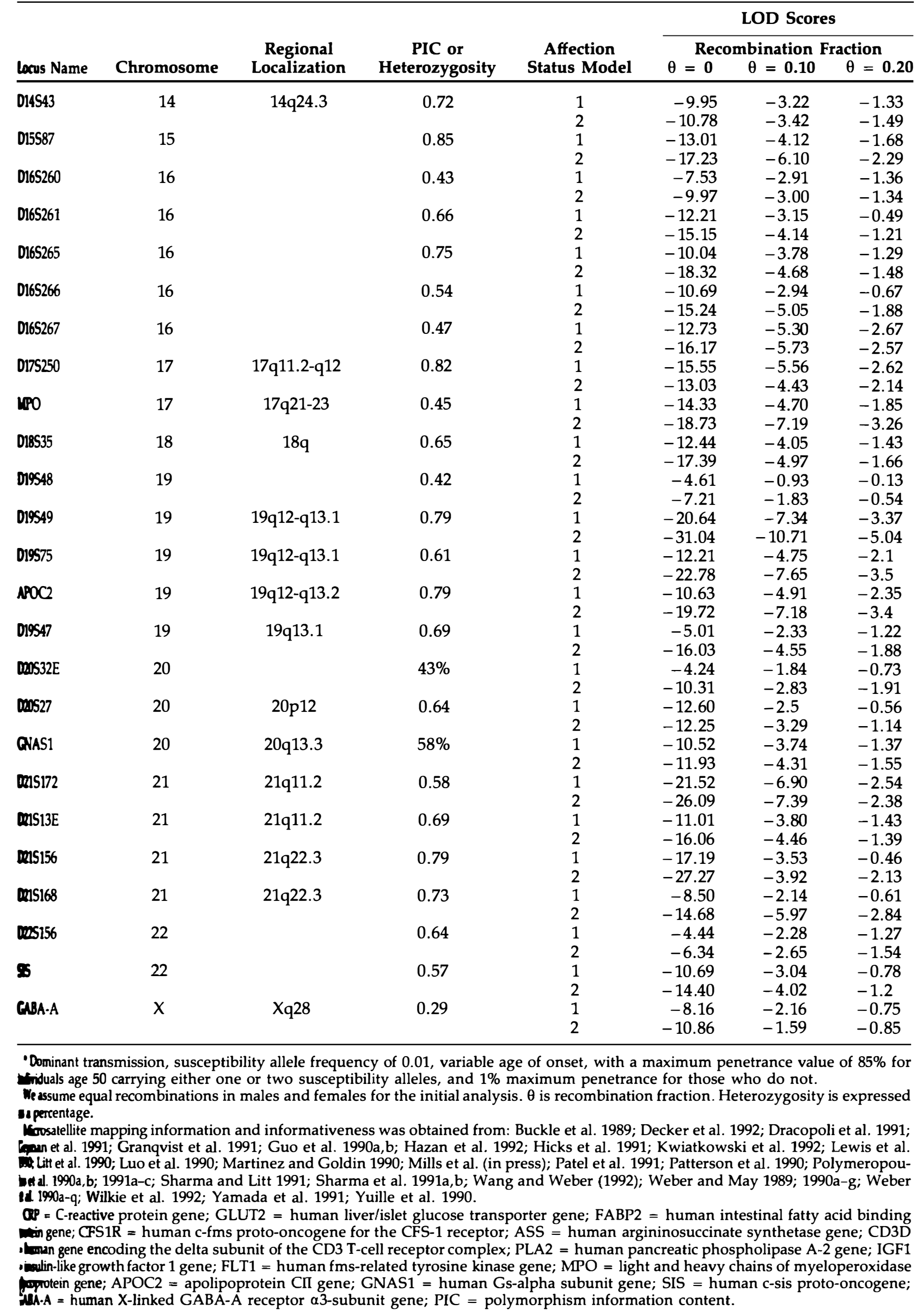


to detect linkage for sample sizes of genotyped individuals of 194,244 , and 305 is $69 \%, 80 \%$, and $90 \%$, respectively. As the recombination fraction increases or the proportion of linked families decreases, the power to detect linkage is lower.

The highest maximum LOD scores for the whole series of pedigrees were at D1S103 with affection status model 2 at 0.3 recombination fraction (1.19); LOD scores are negative with models 1 and 3 .

For this locus, D1S103, as shown in Table 2, family
1482 at $\theta=0$ had $Z_{\max }($ maximum LOD score $)=1.99$ and 2.39 under models 1 and 2 , respectively. These were the highest LOD scores for an individual family in the pedigree series. Other positive LOD scores in individual pedigrees on chromosome 1q were noted: pedigree 1505 , locus D1S117, $Z_{\max }=2.1$ and 0.52 under models 1 and 2, respectively; family 1512 , locus CRP, $Z_{\max }=$ 0.17 and 1.58 under models 1 and 2. Other analyses of loci on the long arm of chromosome 1 did not reveal similar positive scores (Table 3). Our two-point scores

Table 2. LOD Scores for Locus D1S103 Affection Status Models 1 and 2

\begin{tabular}{|c|c|c|c|c|c|c|c|c|}
\hline \multirow[b]{2}{*}{ Family No. } & \multicolumn{8}{|c|}{ Recombination Fraction } \\
\hline & 0.0 & 0.01 & 0.05 & 0.1 & 0.15 & 0.2 & 0.3 & 0.4 \\
\hline \multicolumn{9}{|l|}{ Model 1} \\
\hline 16 & -1.32 & -1.24 & -0.96 & -0.69 & -0.49 & -0.34 & -0.14 & -0.03 \\
\hline 48 & -1.73 & -1.32 & -0.78 & -0.49 & -0.32 & -0.20 & -0.07 & -0.02 \\
\hline 65 & 0.10 & 0.10 & 0.07 & 0.05 & 0.03 & 0.02 & 0.01 & 0.00 \\
\hline 68 & -1.69 & -1.41 & -0.90 & -0.58 & -0.38 & -0.24 & -0.08 & -0.01 \\
\hline 92 & -1.49 & -1.16 & -0.69 & -0.45 & -0.32 & -0.24 & -0.13 & -0.07 \\
\hline 137 & -2.70 & -2.26 & -1.45 & -0.95 & -0.64 & -0.43 & -0.17 & -0.04 \\
\hline 278 & -2.51 & -2.28 & -1.63 & -1.20 & -0.94 & -0.76 & -0.48 & -0.23 \\
\hline 441 & 0.04 & 0.04 & 0.03 & 0.02 & -0.00 & -0.02 & -0.02 & -0.01 \\
\hline 488 & 0.75 & 0.73 & 0.64 & 0.53 & 0.42 & 0.33 & 0.17 & 0.06 \\
\hline 643 & -0.41 & -0.40 & -0.35 & -0.29 & -0.24 & -0.18 & -0.09 & -0.02 \\
\hline 1442 & -0.90 & -0.86 & -0.58 & -0.27 & -0.07 & 0.04 & 0.10 & 0.04 \\
\hline 1482 & 1.99 & 1.94 & 1.76 & 1.54 & 1.31 & 1.08 & 0.63 & 0.24 \\
\hline 1483 & -0.00 & -0.00 & -0.00 & -0.00 & -0.00 & -0.00 & -0.00 & -0.00 \\
\hline 1484 & 0.55 & 0.67 & 0.86 & 0.87 & 0.82 & 0.73 & 0.50 & 0.26 \\
\hline 1505 & -1.12 & -0.88 & -0.49 & -0.29 & -0.18 & -0.11 & -0.04 & -0.01 \\
\hline 1512 & -2.73 & -2.12 & -1.37 & -0.94 & -0.66 & -0.46 & -0.19 & -0.05 \\
\hline 1520 & -1.11 & -0.78 & -0.29 & -0.04 & 0.09 & 0.14 & 0.14 & 0.06 \\
\hline 1536 & -1.68 & -1.56 & -1.22 & -0.93 & -0.73 & -0.58 & -0.35 & -0.18 \\
\hline 9000 & 0.13 & 0.15 & 0.18 & 0.18 & 0.17 & 0.14 & 0.08 & 0.02 \\
\hline Total & -15.82 & -12.67 & -7.17 & -3.94 & -2.14 & -1.06 & -0.12 & 0.00 \\
\hline \multicolumn{9}{|l|}{ Model 2} \\
\hline 16 & -1.32 & -1.24 & -0.96 & -0.69 & -0.49 & -0.34 & -0.14 & -0.08 \\
\hline 48 & -2.15 & -1.82 & -1.06 & -0.60 & -0.34 & -0.18 & -0.03 & 0.01 \\
\hline 65 & -1.46 & -0.54 & -0.10 & 0.09 & 0.14 & 0.15 & 0.10 & 0.03 \\
\hline 68 & -0.61 & -0.36 & 0.03 & 0.19 & 0.25 & 0.24 & 0.15 & 0.06 \\
\hline 92 & -3.28 & -2.80 & -2.23 & -1.83 & -1.46 & -1.12 & -0.58 & -0.23 \\
\hline 137 & -2.70 & -2.26 & -1.45 & -0.95 & -0.64 & -0.43 & -0.17 & -0.01 \\
\hline 278 & -1.11 & -1.00 & -0.54 & -0.19 & 0.01 & 0.13 & 0.21 & 0.15 \\
\hline 441 & 0.42 & 0.41 & 0.38 & 0.33 & 0.26 & 0.20 & 0.07 & 0.00 \\
\hline 448 & 0.75 & 0.73 & 0.64 & 0.53 & 0.42 & 0.33 & 0.17 & 0.06 \\
\hline 643 & -1.82 & -1.64 & -1.19 & -0.84 & -0.60 & -0.41 & -0.17 & -0.01 \\
\hline 1442 & -1.46 & -1.10 & -0.58 & -0.27 & -0.08 & 0.02 & 0.08 & 0.03 \\
\hline 1482 & 2.39 & 2.34 & 2.15 & 1.90 & 1.64 & 1.39 & 0.86 & 0.36 \\
\hline 1483 & 0.06 & 0.06 & 0.05 & 0.04 & 0.03 & 0.02 & 0.01 & 0.00 \\
\hline 1484 & 0.42 & 0.55 & 0.75 & 0.78 & 0.73 & 0.65 & 0.46 & 0.24 \\
\hline 1505 & -1.28 & -1.21 & -0.79 & -0.44 & -0.25 & -0.14 & -0.04 & -0.01 \\
\hline 1512 & -1.43 & -0.35 & 0.22 & 0.38 & 0.40 & 0.37 & 0.22 & 0.06 \\
\hline 1520 & 0.36 & 0.40 & 0.51 & 0.55 & 0.54 & 0.50 & 0.32 & 0.11 \\
\hline 1536 & -1.77 & -1.72 & -1.42 & -1.08 & -0.83 & -0.64 & -0.39 & -0.19 \\
\hline 9000 & 0.97 & 0.96 & 0.87 & 0.76 & 0.65 & 0.53 & 0.31 & 0.13 \\
\hline Total & -15.02 & -10.72 & -4.73 & -1.35 & 0.41 & 1.28 & 1.47 & $0 . \pi$ \\
\hline
\end{tabular}

Pairwise Analysis of BP and D1S103.

Pedigree 9000 is Old Order Amish 110 right extension (Kelsoe et al. 1990).

See Table 1 legend for genetic parameters. 
Table 3. Simulation of Maximum Values of LD Score with Multiple Analyses

\begin{tabular}{|c|c|c|c|c|}
\hline \multirow[b]{2}{*}{ WD Scores } & \multicolumn{2}{|c|}{$\begin{array}{c}\text { No Linkage } \\
(\theta=0.5)\end{array}$} & \multicolumn{2}{|c|}{$\begin{array}{c}\text { Linkage } \\
(\theta=0.01)\end{array}$} \\
\hline & F1505 & F1482 & F1505 & F1482 \\
\hline \multicolumn{5}{|l|}{ Madel 1} \\
\hline $\begin{array}{l}\text { Average } Z_{\max } \\
P\left(Z_{\max }>2\right) \\
P\left(Z_{\max }>3\right)\end{array}$ & $\begin{array}{l}0.20 \\
0.35 \% \\
0.15 \%\end{array}$ & $\begin{array}{l}0.35 \\
0.7 \% \\
0.5 \%\end{array}$ & $\begin{array}{r}1.21 \\
22.3 \% \\
0.0 \%\end{array}$ & $\begin{array}{r}1.92 \\
43.8 \% \\
20.4 \%\end{array}$ \\
\hline \multicolumn{5}{|l|}{ Model 2} \\
\hline $\begin{array}{l}\text { Average } Z_{\max } \\
P\left(Z_{\max }>2\right) \\
P\left(Z_{\max }>3\right)\end{array}$ & $\begin{array}{l}0.25 \\
0.4 \% \\
0.0 \%\end{array}$ & $\begin{array}{l}0.40 \\
0.4 \% \\
0.25 \%\end{array}$ & $\begin{array}{r}1.36 \\
28.2 \% \\
0.0 \%\end{array}$ & $\begin{array}{c}2.53 \\
61.0 \% \\
36.0 \%\end{array}$ \\
\hline
\end{tabular}

Frequency of maximum LOD score $\left(\mathrm{Z}_{\max }\right)$ for families 1482 and 1505 under disease Model 1 and 2, when there is no linkage $(\theta=$ Q5) and true linkage $(\theta=0.01)$ based on 2000 replicates.

between all markers on $1 \mathrm{q}$ in our data are consistent with the published map order as described by Dracopoli t al. (1991) (results not shown).

When penetrance was decreased to $50 \%$ for locus D1S103, the $Z_{\text {max }}$ for all the families was 0.37 at $\theta=$ 0.30 for model 1 and 1.32 at $\theta=0.25$ for model 2 . In the same analysis, family 1482 at $\theta=0$ had $Z_{\max }=1.77$ and 2.34 under models 1 and 2, respectively.

In some analyses at this locus, individuals affected mder a lower classification model (model 1 is highest andmodel 3 is lowest) were considered unknown. The $Z_{\text {an }}$ for all the families was 0.001 at $\theta=0.40$ and 1.32 $\boldsymbol{z} \theta=0.25$ under models 1 and 2 , respectively.

We have also analyzed the Old Order Amish pedi110 with D1S103 and D1S117. LOD scores were dightly positive at D1S103 under model 1 and model 2and negative at D1S117 (see Table 2). When linkage alysis of the Amish pedigree is added the maximum WOD score (under homogeneity) for the whole series of pedigrees at D1S103 is 1.47 at $\theta=0.30$ recombinaim fraction.

Genetic heterogeneity at D1S103 was tested using the admixture test (one-sided test and type I error of 5s). As previously described by Martinez and Goldin (1900), we have modified the MLINK program (V5.03) maximize the LOD score as a function of $\theta$ and of teproportion of linked families (heterogeneity rate), c. Analysis of linkage under heterogeneity (Amish pedmeenot included) revealed a maximum LOD score of $L 8$ at $\theta=0.10, \alpha=0.35$ (heterogeneity test $X_{1}^{2}=2.35$, $p=0.063$ ), affection status model 2 , and a maximum LOD score of 0.75 at $\theta=0, \alpha=0.10$, (heterogeneity ot $\left.X_{1}^{2}=3.45, p=.031\right)$, affection status model 1 . Conetic heterogeneity is thus (weakly) supported, but enidence for genetic linkage is not significant.

For families 1482 and 1505, we estimated the frepency of positive maximum LOD scores greater than 2that could arise by chance alone and when there is a true tight linkage between the marker and the trait locus. Using the SLINK program (Ott 1989; Weeks et al. 1990), 2000 replicates of each family were simulated under disease models 1 and 2 . We have considered a marker locus with four alleles equally frequent either unlinked $(\theta=0.5)$ or tightly linked $(\theta=0.01)$ to the disease locus and maximized the individual pedigree LOD scores (Table 3 ). We have investigated the possibility that multiple linkage analyses would inflate the LOD scores (Clerget-Darpoux et al. 1990; Weeks et al. 1990). Thompson (1984) derived the equivalence of multiple analyses from the significance level of the data with a single linkage test. In a report such as this one, we can consider that 20 to 50 independent markers would provide information in these two families. Assuming that these analyses are independent and that there is no disease locus linked to the tested markers for family 1482 , the probability of observing a LOD score greater than 2 varies from $13 \%$ to $30 \%$ (disease model 1) and from $8 \%$ to $18 \%$ (disease model 2). For family 1505 , this probability varies from $7 \%$ to $16 \%$ (disease model 1 ) and from $8 \%$ to $18 \%$ (disease model 2 ). Thus, when no disease locus exists, there is still a considerable probability of observing at least one LOD score greater than 2 when this many independent analyses are performed.

\section{DISCUSSION}

The problems of detecting a single locus for susceptibility in the psychiatric disorders include conditions of complex inheritance, which may also be present in numerous inherited common diseases. These include variable penetrance (by which is meant that people may have the disease genetic vulnerability but not themselves be ill), genetic linkage heterogeneity, oligogenic inheritance, and density and informativeness of the human genetic map. Nonetheless, linkage may be detectable under conditions of complex inheritance that are compatible with reasonable assumptions based on the observed familial recurrence risks in BP (Goldin et al. 1991).

Polymorphism information content is defined as the probability that an offspring will be informative at a given marker locus. Polymorphism information content values range from 0 (absence of heterozygosity) to 1 (informative in any given meiosis); one can think of a rough numerical equivalence of PIC and of average heterozygosity. Most of the classic RFLP markers consist of biallelic systems that have low PIC values. Dinucleotide repeats generate allele systems formed by more than two alleles (systems of more than 10 alleles are not infrequent) and have high PIC values. Currently, some microsatellite systems fill gaps in the existing genetic map, thus improving its informativeness and resolution (Decker et al. 1992; Dracopoli et al. 1991; 
Hazan et al. 1992; Kwiatkowski et al. 1992; Lewis et al. 1990; Mills et al. [in press]; Wang and Weber 1992; Wang et al. [unpublished data]; Wilkie et al. 1992).

In this paper, a "second pass" with microsatellites generated some isolated positive LOD scores in chromosome 1q. Although LOD scores obtained at locus D1S103 seemed encouraging at first, they could have arisen by chance, given the number of linkage tests performed. Furthermore, in the previous published analysis of this region in these pedigrees (Berrettini et al. 1991b), the nearby markers did not suggest linkage. However, it is worth mentioning that positive LOD scores on chromosome $1 \mathrm{q}$ had been previously reported in the Old Order Amish pedigree 110 at loci in the same area (Pakstis et al. 1991).

Among the markers studied here, there are two possible candidate genes, Gs-alpha subunit-1 and gamma-aminobutyric acid-A (which is in a region previously analyzed [Berrettini et al. 1990]). Our results do not support a causative relationship between these loci and BP.

The availability of a large number of microsatellite systems evenly spanning the human genome, their informativeness, the rapid creation of genetic maps based on them, and the feasibility of multiplexing should make these systems the core of psychiatric genetic mapping in the upcoming years.

\section{ACKNOWLEDGMENT}

This work was supported in part by a grant from Anita Kaskel Roe to the Foundation for Advanced Education in the Sciences. We would like to thank Juliet Guroff and Diane Kazuba for their assistance with the database and Robin Ingraham for her secretarial assistance. We also would like to thank Dr. James Weber for providing information on microsatellite systems.

\section{REFERENCES}

Berrettini WH, Goldin LR, Gelernter J, Gejman P, Gershon ES, Detera-Wadleigh S (1990): X-chromosome markers and manic-depressive illness: Rejection of linkage to Xq28 in nine bipolar pedigrees. Arch Gen Psychiatry 47: 336-373

BerrettiniWH, Goldin LR, Martinez MM, Maxwell ME, Smith AL, Guroff JJ, Kazuba DM, Nurnberger JI, Hamovit J, Simmons-Alling S, Muniec D, Choi H, York C, Robb AS, Gershon ES (1991a): A bipolar pedigree series for genomic mapping of disease genes: Diagnostic and analytic considerations. Psychiatric Genet 2:125-160

Berrettini WH, Detera-Wadleigh SD, Goldin LR, Martinez M, Hsieh W-T, Hoehe M, Choi H, Muniec D, Ferraro TN, Guroff J, Kazuba D, Harris N, Kron E, Nurnberger JI Jr, Alexander RC, Gershon ES (1991b): Genomic screening for genes predisposing to bipolar disease. Psychiatric Genet 2:191-208
Buckle VJ, Fujita N, Ryder-Cook AS, Derry JMJ, Barnard PJ, Lebo RV, Schofield PR, SeeburgPH, Bateson AN, Darlison MG, Barnard EA (1989): Chromosomal localization of GABA-A receptor subunit genes: Relationship to human genetic disease. Neuron 3:647-654

Clerget-Darpoux F, Bonaiti-Pellie C, Hochez J (1986): Effects of misspecifying genetic parameters in lod score analysis. Biometrics 42:393-399

Clerget-Darpoux F, Babron MC, Bonaiti-Pellie C (1990): Assessing the effect of multiple linkage tests in complex diseases. Genet Epidemiol 7:245-254

Decker RA, Moore J, Ponder B, Weber JL (1992): Linkage mapping of human chromosome 10 microsatellite polymorphisms. Genomics 12:604-606

Detera-Wadleigh SD, Berrettini WH, Goldin LR, Martinez M, Hsieh W-T, Hoehe MR, Encio IJ, Coffman D, Rollins DY, Muniec D, Choi H, Guroff J, Wiesch D, Thai N, Gershon ES (1992): A systematic search for a bipolar predisposing locus on chromosome 5. Neuropsychopharmacology 6:219-229

Dracopoli NC, O'Connell P, Elsner TI, Lalouel J-M, White RL, Buetow KH, Nishimura DY, Murray JC, Helms C, Mishra SK, Donis-Keller H, Hall JM, Lee MK, King M-C, Attwood J, Morton NE, Robson EB, Mahtani M, Willard HF, Royle NJ, Patel I, Jeffreys AJ, Verga V, Jenkins T, Weber JL, Mitchell AL, Bale AE (1991): The CEPH ${ }^{1}$ consortium linkage map of human chromosome 1 . Genomics 9:686-700

Gejman PV, Detera-Wadleigh S, Martinez M-M, Berrettini WH, Goldin LR, Gelernter J, Hsieh W-T, Gershon ES (1990): Manic depressive illness not linked to factor XX region in an independent series of pedigrees. Genomics 8:648-655

Gejman PV, Weinstein LS, Martinez M, Spiegel AM, CaoQ, Hsieh W-T, Hoehe MR, Gershon ES (1991): Genetic map ping of the Gs-alpha subunit gene (GNAS1) to the distal long arm of chromosome 20 using a polymorphism detected by denaturing gradient gel electrophoresis. Genomics 9:782-783

Goldin LR, Martinez MM, Gershon ES (1991): Sampling strategies for linkage studies. Eur Arch Psychiatry Clin Neurosci 240:182-187

Granqvist M, Xiang K, Seino M, Bell GI (1991): Dinucleotide repeat polymorphism in Gs-subunit gene (GNAS1) on chromosome 20. Nucl Acids Res 19:4569 (Abstract)

Guo Z, Sharma V, Litt M (1990a): Dinucleotide repeat poly. morphism at the D21S13E locus. Nucl Acids Res 18:740 (Abstract)

Guo Z, Sharma V, Patterson D, Litt M (1990b): Dinucleotide repeat polymorphism at the D21S168 locus. Nucl Acids Res 18:5924 (Abstract)

Hazan J, Dubay C, Pankowiak M-P, Becuwe N, Weissenbach J (1992): A genetic linkage map of human chromosome 20 composed entirely of microsatellite markers. Genomis 12:183-189

Hicks AA, Johnson KJ, Barnard EA, Darlison MG (1991): Dinucleotide repeat polymorphism in the human X-linked GABA A receptor alpha3-subunit gene. Nucl Acids Res 19:4016 (Abstract)

Kelsoe JR, Ginns EI, Egeland JA, Gerhard DS, Goldstein AM Bale SJ, Pauls DL, Long RT, Kidd KK, Conte G, Hous 
man DE, Paul SM (1990): Re-evaluation of the linkage relationship between chromosome $11 p$ loci and the gene for bipolar affective disorder in the Old Order Amish. Nature 342:238-243

Kwiatkowski DJ, Henske EP, Weimer K, Ozelius L, Gusella JF, Haines J (1992): Construction of a GT polymorphism map of human $9 \mathrm{q}$. Genomics 12:229-240

Ithrop GM, Lalouel JM, Julier C, Ott J (1985): Multilocus linkage analysis in humans: Detection of linkage and estimation of recombination. Am J Hum Genet 37:382-498

Lwis JG, Weber JL, Petersen MB, Slaugenhaupt SA, Kwitek A, May PE, Warren AC, Chakravarti A, Antonarakis SE (1990): Linkage mapping of the highly informative DNA marker D21S156 to human chromosome 21 using a polymorphic GT dinucleotide repeat. Genomics 8: 400-402

ItM, Sharma V, Luty JA (1990): Dinucleotide repeat polymorphism at the D11S35 locus. Nucl Acids Res 18:5921 (Abstract)

Ino Y, Evans GA, Litt M (1990): Dinucleotide repeat polymorphism at the D11S420 locus. Nucl Acids Res 18:7470 (Abstract)

M-tinez MM, Goldin LR (1990): Power of the linkage test for a heterogeneous disorder due to two independent inherited causes: A simulation study. Genet Epidemiol 7:219-230

10.3KA, Buetow KH, Xu Y (1992): Genetic and physical maps of human chromosome 4 based on dinucleotide repeats. Genomics (in press)

Numberger JI Jr, Goldin LR, Gershon ES (1986): Genetics of psychiatric disorders. In Winokur G, Clayton P (eds), The Medical Basis of Psychiatry. Philadelphia, WB Saunders, Pp 486-521

Ou (1989): Computer-simulation methods in human linkage analysis. Proc Natl Acad Sci USA 86:4175-4178

Ptetis AJ, Kidd JR, Castiglione CM, Kidd KK (1991): Status of the search for a major genetic locus for affective disorder in the Old Order Amish. Hum Genet 87:475-483

لـP, Lo YMD, Bell GI, Turner RC, Wainscoat JS (1991): Dinucleotide repeat polymorphism at the human GLUT2 locus. Nucl Acids Res 19:4017 (Abstract)

Puson H, Mitchell PJ, Cooper CS, Stratton MR (1990): Dinucleotide repeat polymorphism at the SISlocus. Nucl Acids Res 18:5917 (Abstract)

Ponghman LM, Boehnke M (1989): Estimating the power of a proposed linkage study for a complex genetic trait. Am J Hum Genet 44:543-551

ejereropoulos MH, Rath DS, Xiao H, Merril CR (1990a): Trinucleotide repeat polymorphism at the human intestinal fatty acid binding protein gene (FABP2). Nucl Acids Res 18:7198 (Abstract)

Qjueropoulos MH, Rath DS, Xiao H, Merril CR (1990b): Trinucleotide repeat polymorphism at the human panceatic phospholipase A-2 gene (PLA2). Nucl Acids Res 18:7468 (Abstract)

Qjmeropoulos MH, Rath DS, Xiao H, Merril CR (1991a): Dinucleotide repeat polymorphism at the human fmsrelated tyrosine kinase gene (FLT1). Nucl Acids Res 19:2803 (Abstract)

Pforepoulos MH, Xiao H, Rath DS, Merril CR (1991b):
Dinucleotide repeat polymorphism at the human c-fms proto-oncogene for the CFS-1 receptor (CFS1R). Nucl Acids Res 19:1160 (Abstract)

Polymeropoulos MH, Xiao H, Rath DS (1991c): Dinucleotide repeat polymorphism at the human gene of the light and heavy chains of myeloperoxidase glycoprotein (MPO). Nucl Acids Res 19:1961 (Abstract)

Sharma V, Litt M (1991): Dinucleotide repeat polymorphism at the D1S117 locus. Nucl Acids Res 19:1168 (Abstract)

Sharma V, Allen L, Magenis RE, Litt M (1991a): Dinucleotide repeat polymorphism at the D21S172 locus. Nucl Acids Res 19:1169 (Abstract)

Sharma V, Smith K, Allen L, Magenis RE, Litt M (1991b): Dinucleotide repeat polymorphism at the D14S43 locus. Nucl Acids Res 19:1722 (Abstract)

Smith CAB (1963): Testing for heterogeneity of recombination fraction values in human genetics. Ann Hum Genet 27:175-182

Thompson EA (1984): Interpretation of LOD scores with a set of marker loci. Genet Epidemiol 1:357-362

Wang Z, Weber JL (1992): Continuous linkage map of human chromosome 14 short tandem repeat polymorphisms. Genomics 13:532-536

Weber JL, May PE (1989): Abundant class of human DNA polymorphisms which can be typed using the polymerase chain reaction. Am J Hum Genet 44:388-396

Weber JL, May PE (1990a): Dinucleotide repeat polymorphism at the D2S72 locus. Nucl Acids Res 18:2200 (Abstract)

Weber JL, May PE (1990b): Dinucleotide repeat polymorphism at the D3S240 locus. Nucl Acids Res 18:2201 (Abstract)

Weber JL, May PE (1990c): Dinucleotide repeat polymorphism at the D20S27 locus. Nucl Acids Res 18:2202 (Abstract)

Weber JL, May PE(1990d): Dinucleotide repeat polymorphism at the D9S43 locus. Nucl Acids Res 18:2203 (Abstract)

Weber JL, May PE (1990e): Dinucleotide repeat polymorphism at the D10S89 locus. Nucl Acids Res 18:4637 (Abstract)

Weber JL, May PE(1990f): Dinucleotide repeat polymorphism at the D22S156 locus. Nucl Acids Res 18:4639 (Abstract)

Weber JL, May PE (1990g): Dinucleotide repeat polymorphism at the D18S35 locus. Nucl Acids Res 18:6465 (Abstract)

Weber JL, Kappel C, May PE, Kwitek AE (1990a): Dinucleotide repeat polymorphism at the D19S75 locus. Nucl Acids Res 18:4639 (Abstract)

Weber JL, Kwitek AE, May PE (1990b): Dinucleotide repeat polymorphism at the D1S103 locus. Nucl Acids Res 18:2199 (Abstract)

Weber JL, Kwitek AE, May PE (1990c): Dinucleotide repeat polymorphism at the D1S104 locus. Nucl Acids Res 18:2835 (Abstract)

Weber JL, Kwitek AE, May PE (1990d): Dinucleotide repeat polymorphisms at the D16S260, D16S261, D16S265, D16S266, and D16S267 loci. Nucl Acids Res 18:4034 (Abstract

Weber JL, Kwitek AE, May PE (1990e): Dinucleotide repeat polymorphisms at the D5S107, D5S108, D5S111, D5S117 and D5S118 loci. Nucl Acids Res 18:4035 (Abstract)

Weber JL, Kwitek AE, May PE (1990f): Dinucleotide repeat 
polymorphisms at the D11S419 and CD3D loci. Nucl Acids Res 18:4036 (Abstract)

Weber JL, Kwitek AE, May PE (1990g): Dinucleotide repeat polymorphisms at the 7S435 and D7S440 loci. Nucl Acids Res 18:4039 (Abstract)

Weber JL, Kwitek AE, May PE (1990h): Dinucleotide repeat polymorphism at the CRP locus. Nucl Acids Res 18:4635 (Abstract)

Weber JL, Kwitek AE, May PE (1990i): Dinucleotide repeat polymorphism at the D6S87 locus. Nucl Acids Res 18:4636 (Abstract)

Weber JL, Kwitek AE, May PE (1990j): Dinucleotide repeat polymorphism at the D13S71 locus. Nucl Acids Res 18:4638 (Abstract)

Weber JL, Kwitek AE, May PE (1990k): Dinucleotide repeat polymorphism at the D15S87 locus. Nucl Acids Res 18:4640 (Abstract)

Weber JL, Kwitek AE, May PE, Killary AM (19901): Dinucleotide repeat polymorphism at the D4S174 locus. Nucl Acids Res 18:4636 (Abstract)

Weber JL, Kwitek AE, May PE, Patterson D, Drabkin H (1990m): Dinucleotide repeat polymorphisms at the D8S85, D8S87, and D8S88 loci. Nucl Acids Res 18:4038 (Abstract)

Weber JL, Kwitek AE, May PE, Polymeropoulos M (1990n): Dinucleotide repeat polymorphism at the D12S43 locus. Nucl Acids Res 18:4637 (Abstract)
Weber JL, Kwitek AE, May PE, Wallace MR, Collins FS, Ledbetter DH (1990o): Dinucleotide repeat polymorphisms at the D17S250 and D17S261 loci. Nucl Acids Res 18:4640 (Abstract)

Weber JL, May PE, Kappel C (1990p): Dinucleotide repeat polymorphism at the D19S49 locus. Nucl Acids Res 18:1927 (Abstract)

Weber JL, May PE, Patterson D, Drabkin H, Killary AM (1990q): Dinucleotide repeat polymorphism at the D3S1\% locus. Nucl Acids Res 18:4635 (Abstract)

Weeks DE, Ott J, Lathrop GM (1990): SLINK: A general simu. lation program for linkage analysis. Am J Hum Genel 47:A204 (Abstract)

Wijmenga C, Frants RR, Brouwer OF, Moerer P, Weber JL, Padberg GW (1990): Location of facioscapulohumeral muscular dystrophy gene on chromosome 4 . Lancet 336:651-653

Wilkie PJ, Krizman DB, Weber JL (1992): Linkage map of human chromosome 9 microsatellite polymorphisms. Genomics 12:607-609

Yamada Y, Xiang K-S, Bell GI, Seino S, Nishi M (1991): Dinucleotide repeat polymorphism in a gene on chromosome 20 encoding a G-protein coupled receptor (D20S32E). Nucl Acids Res 19:2519 (Abstract)

Yuille MAR, Hampson RM, Harris RM, Affara NA (1990): CA repeat polymorphism at the ASS locus. Nucl Acids Res 18:7472 (Abstract) 